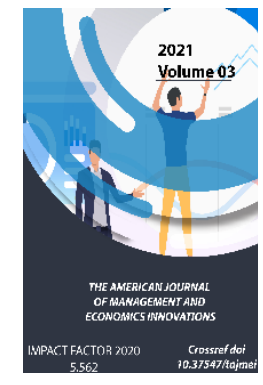

Journal Website: http://theamericanjour nals.com/index.php/taj mei

Copyright: Original content from this work may be used under the terms of the creative commons attributes 4.0 licence.

\section{Opportunities For Effective Use Of Digital Banking Services In The Effective Management Of Financial Resources Of}

\section{Commercial Banks In A Pandemic}

\author{
Uygun Ortikov \\ Candidate Of Economic Sciences, Associate Professor, Head Of Banking Faculty, Tashkent \\ Institute Of Finance, Uzbekistan
}

\title{
ABSTRACT
}

This article discusses the introduction of new banking services in the management of financial resources of commercial banks, the effective use of digital bookkeeping services, the rational management of bank resources in a pandemic and modern services. Also, in this article discusses how the COVID-19 pandemic is impacting the digital transformation, how many business owners and organizations are trying to further enhance digital technologies during the pandemic, not only in business, but also on their national government portals. Further intensification of transformations was highlighted and analyzed with statistical data. In addition, the pandemic affects many sectors of the economy, especially the growing demand for online banking services in the banking system and various transactions from mobile applications of banks, the fact that commercial banks offer customers a variety of digital banking services are shown on the basis of data.

\section{KEYWORDS}

COVID-19, digital transformation, economic crisis, digital innovative technologies, long-term investment, public services, e-government, online banking, digital banking, digital marketing, mobile applications, online online transactions.

\section{INTRODUCTION}

It is known that in recent years, the banking and financial sector in Uzbekistan has been gradually reformed, a number of measures have been taken, and as a result, the necessary legal conditions have been created to conduct advanced banking business and 
strengthen the competitive environment. During the COVID-19 pandemic, additional measures should be taken to increase the popularity of financial services provided by banks, expand the access of banks to the regions and ensure the provision of the same type of services in all settlements.

Today, the world is facing a more serious economic crisis than it witnessed during the global financial crisis. The coronavirus pandemic has dealt a major blow to the world's economies. In almost a week, many workers lost their jobs and jobs. Restaurants, hotels and planes were all empty. Consumers and businesses are now facing sharp losses in their revenues, and bankruptcies are on the rise. Pressure on the banking system is growing and more default risks on loans are expected to increase. Many countries are expecting major blows to the financial sector, similar to the 2008 crisis [1].

The coronavirus pandemic is having a serious impact on social life and the economy. How are digital companies doing in this time of crisis? Will the crisis really lead to a digital transformation? COVID-19: "Is there a threat or opportunity - what are the consequences of a coronavirus pandemic for the digital industry?" Of course, the social and economic impact of the COVID-19 pandemic is currently difficult to predict. In addition to public health concerns, the risk of a serious economic crisis is also high. Due to initial restrictions, the future of several firms remained uncertain; others began to think that they needed to radically reconsider their approaches and develop a different culture of labor.

As the great Greek philosopher Plato put it, "Need is the mother of all inventions." [2] Indeed, once the coronavirus pandemic began to take over the world, all business owners began to think about how to save their business. While digital transformation has long been a major agenda for most organizations, the COVID-19 pandemic has made serious and progressive-minded organizations feel the need to step up digital transformation.

Of course, what is the "digital transformation" for everyone? It is natural to ask. "Digital transformation" means the introduction of new digital technologies in all areas and the solution of problems through them. Today, almost all advanced business owners have introduced it into their businesses so that they can keep up to date with information about their business. The following table shows several advantages of the digital marketing transformation: [Table 1] 
Table-1

Advantages of Implementing Digital Marketing [3]

\begin{tabular}{|c|c|}
\hline Digital Marketing & Transformation effect \\
\hline Digital materials & $\begin{array}{l}\text { Reduces the cost of printing and distribution, enabling the } \\
\text { evaluation of business processes based on digital } \\
\text { communications. }\end{array}$ \\
\hline $\begin{array}{l}\text { Email all customers at the same } \\
\text { time }\end{array}$ & $\begin{array}{l}\text { Reduces the cost of printing and postage, attracting a wider } \\
\text { audience. }\end{array}$ \\
\hline Advertising on social networks & Ability to target a target audience. \\
\hline Website and e-commerce sites & Makes it possible to eliminate rent and utilities. \\
\hline Mobile applications & $\begin{array}{l}\text { Save a lot of extra costs with the ability to put everything } \\
\text { together in one place and the features of direct contact } \\
\text { with customers. }\end{array}$ \\
\hline
\end{tabular}

COVID-19 demonstrated the importance of digital readiness, which allows business and life to continue as usual - as much as possible during a pandemic. Supporting the digital world and building the infrastructure needed to introduce the latest technologies underscores the need for any enterprise or country to remain competitive in the postCOVID-19 world, as well as a human factorbased and inclusive approach to technology management.

The need for the government to accelerate the introduction of digital innovative technologies.

The digital transformation is important not only for business representatives, but also for government portals, e-government system during the pandemic. It is recommended that the government make full use of digital technologies to combat the COVID-19 pandemic and address many of the pandemicrelated challenges based on new and concise data released by the UN Ministry of Economic and Social Affairs [4].

The pandemic is forcing governments and societies to turn to digital technologies to respond to the crisis, and increasingly requires governments to adopt an open government approach and use digital communication channels to obtain reliable information about global, national COVID-19. Blocking and other social restraint measures are in place in most countries, and as people rely on the Internet 
for more information and advice, governments are required to introduce effective digital technologies to prevent outbreaks. In short, a review of the national portals of 193 UN member states showed that as of March 25, 2020, 57 percent (110

$$
\begin{array}{r}
100 \% \\
90 \% \\
80 \% \\
70 \% \\
60 \% \\
50 \% \\
40 \% \\
30 \% \\
20 \% \\
10 \% \\
0 \%
\end{array}
$$

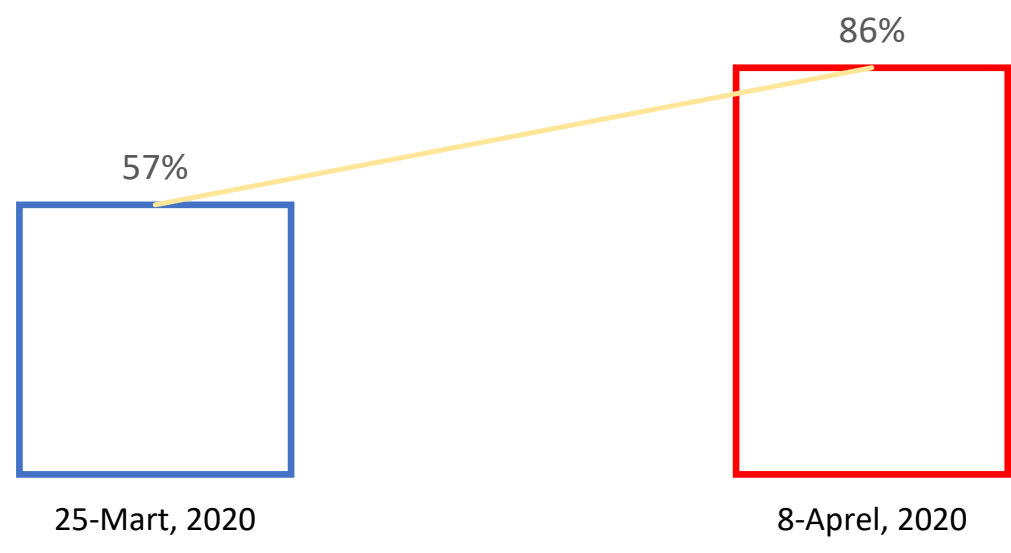

]

Figure 1. As of March-April 2020, what percentage of UN member states regularly publish news about Covid-19 on their official government portals [5].

According to the data, digital transformations and technologies introduced during the pandemic period, the bulk of fintechs are in the private sector. However, the crisis requires the effective provision of public services, which is why each state is required to further strengthen the digital transformation in order to provide its government services to citizens in a safe and sanitary manner, and effective and fast egovernment It is said that it is expedient to provide the system to the citizens.

Through the creation of effective publicprivate partnership technologies, the exchange of experiences and tools, countries can achieve the recovery of their economies and help their communities. Developing countries, in particular, need international cooperation and assistance to mitigate the crisis. Therefore, it is necessary to carry out countries) had access to COVID-19 on their official website. about 43 percent (83 countries) do not. But as of April 8, 2020, about 86 percent (167 countries) had published COVID-19 information and guidelines on their portals. [Figure 1 project, regional, national and local cooperation with private sector companies, international organizations and other stakeholders. In the long run, governments need to accelerate the introduction of innovative digital technologies such as artificial intelligence-enabled technologies, blockchain and drones. It is clear that longterm investment in these technologies will do much to support the future sustainability of health, the economy, and utilities during and after the pandemic.

We can see the growth of digital transformations not only in the commercial sector, but also in the banking and financial system. Due to the COVID-19 pandemic, less use of cash is recommended. In this regard, in order to reduce the likelihood of the spread of infection during the quarantine period in our 
country, according to the recommendations of the Republican Special Commission: [6]

- Payment of pension payments by bank cards to pensioners living in Tashkent and Nukus and regional centers at the initial stage, ie from May this year;

- In the coming months, these measures will be gradually continued in the remaining areas.
In addition to the above, many commercial banks offer customers the use of mobile applications, ie online banking services. For example, the Silk Road Bank offers citizens the opportunity to order plastic cards such as UzCard, Humo, Visa and UnionPay through the application. [Figure 2] You do not have to be a customer of Silk Road Bank to do this. All you have to do with the application is:

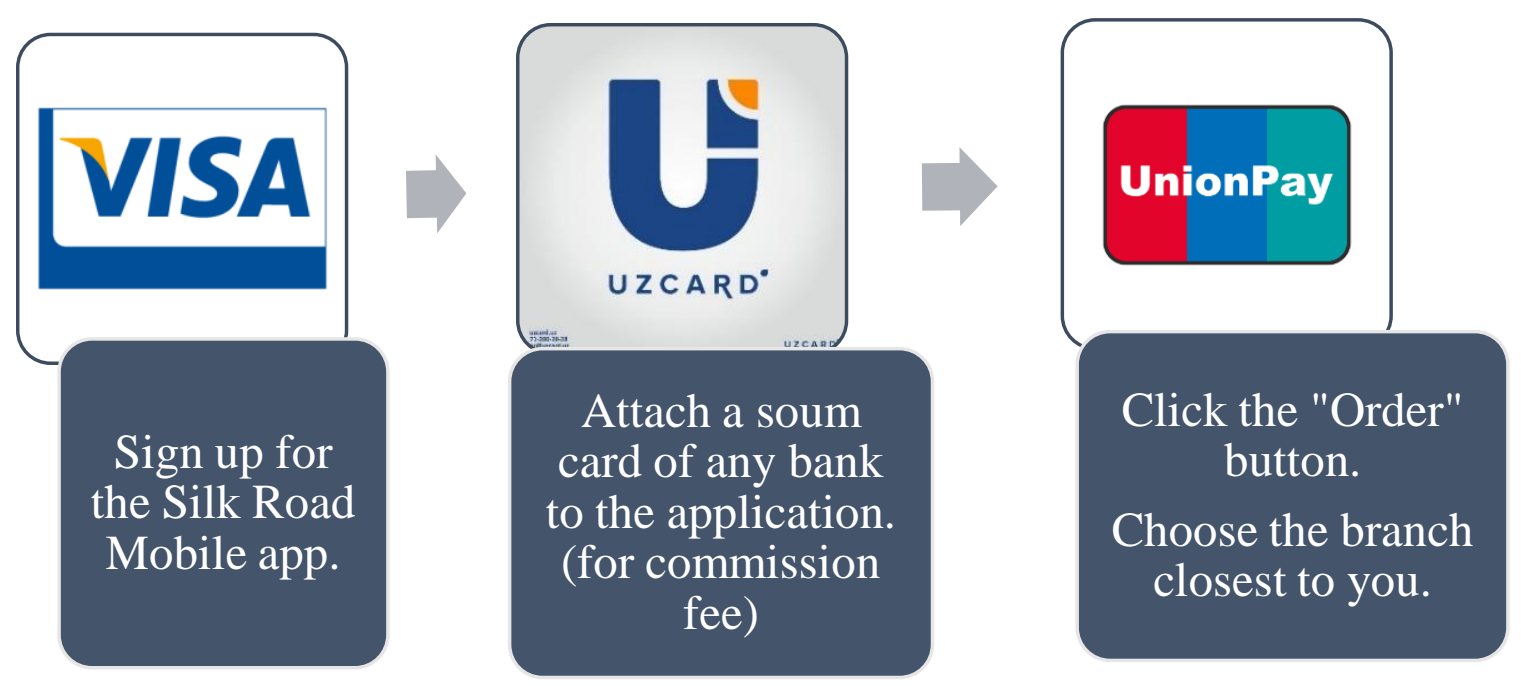

Figure 2. How to order plastic cards through the mobile application "Silk Road" [7]

In addition, citizens can now convert foreign currency into soums or perform reverse transactions through the mobile applications of commercial banks, which require citizens to have a Visa card and UzCard or Humo. Examples of such commercial banks are Turonbank, Xalq Bank, Agrobank, Ipoteka Bank, Hamkorbank and Ipak Yuli [8].

Despite the quarantine, people still feel the need for banking services, which requires banks to intensify digital transformations.
Many banks, on their official websites and social media pages, are constantly providing

their customers with detailed information about the types of services provided by the bank, digital banking services and available online. These online banking services include the convenience for customers to make any transactions around the clock and constant access to all financial information in real time. The following figure shows the percentage of online banking services used during the quarantine period by age of European citizens. [Figure 3] 


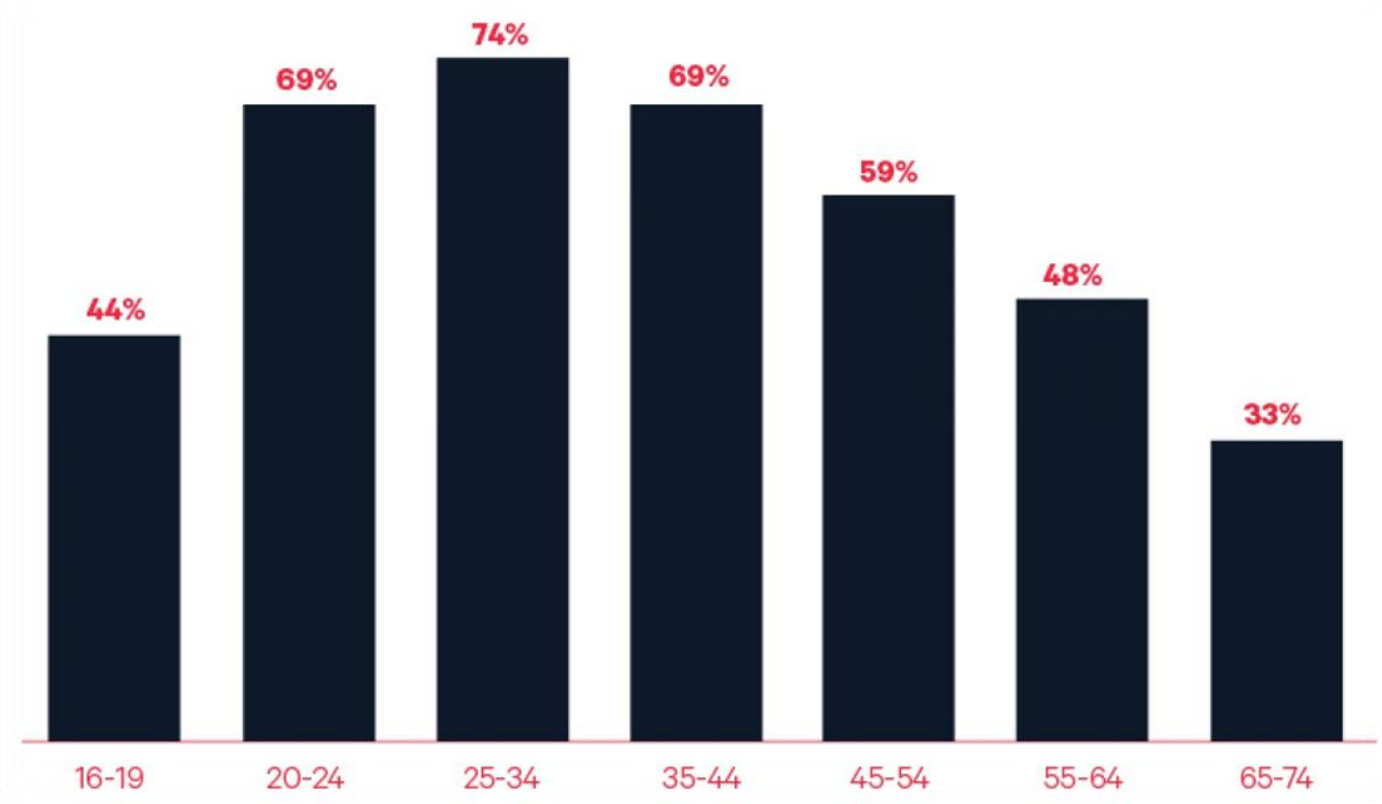

Figure 3. The amount of online banking services for young people in European countries during COVID-19 [9]

The figure shows that the highest rate falls on 25-34 year olds and $74 \%$ of them use online banking services during the pandemic, while the lowest rate is recorded by 65-74 year olds. Only 33\% felt the need for online banking services.

In summary, according to health recommendations, one of the most effective ways to prevent the COVID-19 epidemic today is to avoid personal contact with others. This means reducing people's movement and increasing the amount of time they spend at home as much as possible. In any case, while the introduction of digitalization in all sectors is associated with pandemics and health care constraints, it is clear that this will lead to positive changes in the medium and long term. Even before this pandemic, 70 percent of companies in developed countries had made or were working on digital changes [10].
But COVID-19 has forced companies to accelerate and implement new digital transformation initiatives. The pandemic is having a negative impact on all sectors, after which it is expected that it will take a long time for people to return to their previous lifestyles, or people may have to radically change their lifestyles, their business processes. For this reason, the introduction of digital transformations is equally beneficial for all.

To enhance the digital transformation and survive the pandemic, entrepreneurs and commercial banks are invited to:

- All entrepreneurs need to introduce online services to sustain their business activities so that they can remotely inform their customers about the types of products and services, which is the same during a pandemic. 
- Each country should further strengthen egovernment services, which will ensure the transparency of the relationship between government and citizens, as well as provide citizens with access to government services during the quarantine period without leaving home.

- Banks should increase the number of online services for citizens, in particular, offer banking services that allow them to get online loans, microloans, which is equally beneficial not only for the health of bank employees, but also for the health of customers.

\section{REFERENCES}

1. Electronic source. URL: https://www.imf.org/en/Topics/imfand-covid19/Policy-Responses-toCOVID-19.

2. Electronic source. URL: https://www.phrases.org.uk/meanings /necessity-is-the-mother-of invention.html.

3. Table 1. https://www.salesforce.com/products/ platform/examples-of-digitaltransformation/. Prepared by the author based on information from the site.

4. United Nations Department of Economic and Social Affairs. "Digital technologies are critical to the COVID19 pandemic." https://www.un.org/development/des a/en/news/policy/digital-technologiescritical-in-facing-covid-19pandemic.html.

5. Figure 1. https://www.un.org/development/des a/en/news/policy/digital-technologiescritical-in-facing-covid-19pandemic.html. Prepared by the author based on information from the site.

6. Electronic source. URL: www.cbu.uz.

7. Figure

2. https://ipakyulibank.uz/news/2020-0421-and-application-of-the-cards-tocards--and-delivery-in-the-opportunity. Prepared by the author based on information from the site.

8. Online-briefing by the Central Bank of the Republic of Uzbekistan on April 15, 2020. Electronic source. URL: https://cbu.uz/oz/.

9. Figure 3. Electronic source. URL: (https://www.icarvision.com/en/theimpact-of-covid-19-on-the-use-ofonline-banking.

10. An article entitled How COVID-19 Accelerates Digital Transformation in the Workplace. https://blog.smarp.com/how-covid-19is-accelerating-digital-transformationin-the-workplace. 